\title{
As competências gerenciais dos reitores de universidades federais em Minas Gerais: a visão da alta administração
}

\author{
The managerial competencies of the deans of federal universities in Minas Gerais: the \\ perception of top management
}

Angelo Brigato Ésther ${ }^{1}$

\begin{abstract}
Resumo
No âmbito da gestão empresarial, há muito se discute a questão das competências gerenciais, cuja articulação deve culminar com o alcance dos objetivos organizacionais. Tal lógica tem penetrado o domínio da gestão pública. As universidades públicas, especialmente as federais, vêm experimentando mudanças em sua atuação desde meados da década de 1990, quando se buscou a implementação da chamada "gestão pública gerencial". O objetivo do artigo é analisar as competências atribuídas aos reitores de universidades federais, com a expectativa de contribuir para maior compreensão de sua ação. Para tanto, foram entrevistados reitores, vice-reitores e pró-reitores de oito universidades federais, todas localizadas em Minas Gerais. Os resultados expressam a predominância da competência política, faltando-Ihes, entretanto, o domínio de outras consideradas relevantes para os gestores públicos.
\end{abstract}

Palavras-chave: Gestão universitária. Competências gerenciais. Competência política. Competências dos reitores.

\begin{abstract}
In the context of the business management managerial competencieshave been discussed, and their articulation should culminate with the achievement of organizational goals. This logic has penetrated the field of public administration. The federal universities have been implementing changes since the mid-1990s, when the government attempted to implement the "managerial public administration" philosophy. The aim of the paper is to analyze the competenciesattributed to the presidents of federal universities, with the expectation of contributing to a greater understanding of their actions. For this purpose, deans vice chancellors and pro-rectors from eight federal universities, all of which are located in Minas Gerais State, were interviewed. The results show the dominance of political competence, albeit lacking the domination of others considered relevant for public managers.
\end{abstract}

Keywords: University administration. Managerial competencies. Political competence. Rectors' competencies.

Artigo submetido em 06 de dezembro de 2010 e aceito para publicação em 06 de maio de 2011.

1 Doutor em Administração pelo CEPEAD/UFMG; Professor Adjunto da Faculdade de Administração e Ciências Contábeis da Universidade Federal de Juiz de Fora. Endereço: Rua José Lourenço Kelmer, s/n - Campus Universitário, São Pedro, CEP 36036900. E-mail: angelo.esther@ufjf.edu.br 


\section{Introdução}

Atualmente, com a crescente importância que as organizações assumiram na sociedade - a ponto de Chanlat (2000) falar em sociedade managerialista -, a função gerencial é cada vez mais exposta, atribuindo-se a ela uma maior importância pelo sucesso das organizações, sobretudo no caso das empresas. Por outro lado, o contexto atual vem exigindo das organizações públicas, em todas as esferas (municipal, estadual e federal), uma atuação diferenciada, o que implica uma forma de gestão também diferenciada. Nesse sentido, destacam-se alguns estudos acerca da necessidade de gestores públicos desenvolverem determinadas competências, de modo a contribuírem para o alcance dos resultados de suas organizações.

No âmbito da gestão empresarial, há muito se discute a questão das competências gerenciais, cuja articulação deve culminar com o alcance dos objetivos organizacionais, expressos, geralmente, em forma de resultados quantitativos e econômicos. No âmbito da gestão pública, os objetivos são complexos e muitas vezes ambíguos, exigindo dos gestores uma lógica de ação particular. Entretanto, a lógica empresarial tem penetrado o domínio da gestão pública, implicando mudanças na forma como os gestores atuam.

As universidades públicas, especialmente as federais, vêm experimentando e sofrendo mudanças em sua atuação desde meados da década de 1990, quando se buscou a implementação de uma filosofia chamada de "gestão pública gerencial" para o setor público brasileiro. Se, de um lado, o governo de Fernando Henrique Cardoso visou alterar o estatuto das universidades, impingindo-lhes um caráter em parte empresarial, de outro, o governo Lula visou recuperar o caráter público da instituição. Entretanto, a filosofia de resultados foi mantida. É nesse contexto, no caso brasileiro, que os gestores das universidades devem gerenciar suas instituições, e de posse de determinadas competências.

Diante do exposto, o objetivo do artigo é analisar as competências dos gestores de universidades federais, atribuídas pelos próprios gestores, a partir do caso daquelas instaladas no estado de Minas Gerais, com a expectativa de contribuir para maior compreensão de sua ação e dos desafios que lhe são colocados.

\section{Setor Público: Contexto e Competências para a Gestão}

A administração pública vem sendo alvo de críticas há muito tempo, o que suscita a discussão acerca da necessidade de reformas e mudanças em sua estrutura e dinâmica. Parte dessa crítica pode ser entendida como decorrente de uma questão maior e mais profunda, que é o chamado conflito de sistemas (KURZ, 1993), ou seja, uma espécie de disputa entre um sistema capitalista e um sistema socialista. Com o suposto fim do socialismo (KURZ, 1993), a decadência do modelo fordista enquanto modo de desenvolvimento e a intensificação da globalização (LIPIETZ, 1991), o modelo neoliberal passou a predominar nos países de economia avançada. A perspectiva neoliberal pressupõe a existência de um Estado mínimo e uma crença de que as distorções sociais e econômicas serão superadas por meio da interação espontânea das forças de mercado. O papel do Estado consistiria apenas em assegurar as condições de funcionamento da dinâmica desse mercado, que é apoiado num regime de concorrência (TENÓRIO, 1997).

No caso brasileiro, em especial, o Estado assumiu um papel importante na industrialização do país, constituindo-se, até mesmo, em elo fundamental para a inserção na economia internacional. A ação do Estado empresário (por meio das empresas estatais) brasileiro ocorre principalmente dos anos de 1930 até meados de 1985 (TENÓRIO, 1997). Com o "enxugamento" do Estado (no país e no mundo), incluindo os programas de privatização, este passou a se afastar cada vez mais de certas atividades produtivas até então por ele desempenhadas diretamente, tais como telecomunicações, transportes e energia.

Segundo Bresser Pereira (1996), no Brasil, nos anos de 1980, assistiu-se à crise do Estado, em termos fiscal, das estratégias de intervenção e da forma burocrática pela qual ele é administrado. Se em decorrência disso 
alcançou-se um processo de desaceleração econômica e o aumento de níveis de desemprego, o caminho não seria provocar o definhamento do Estado, mas sim fortalecê-lo.

O modelo tradicional da gestão pública é de inspiração weberiana, e sua crise começa tão logo os Estados buscam alcançar o chamado "Estado de Bem-Estar". Com a expansão da capacidade de prestação de serviços públicos, a condução administrativa por parte da classe política e dos burocratas profissionais começou a apresentar sérias deficiências, o que levou ao surgimento do fenômeno gerencial. No entanto, é no interior do próprio Estado de bem-estar que o modelo gerencial emerge, em função tanto de sua emergência quanto de sua consequente crise fiscal e de escassez de recursos (LONGO, 2003).

A partir do exemplo da Inglaterra, o autor explica que, quando o elevado nível dos gastos públicos e a necessidade de políticas orçamentárias restritivas colocaram em xeque a viabilidade do modelo, foi preciso introduzir disciplina no sistema; ou seja, foram incorporados os managers, ou dirigentes, públicos. Tal processo ocorreu como uma forma tanto de reação da classe política destinada a controlar a coalizão buroprofissional quanto de controle e redução dos gastos públicos (LONGO, 2003).

Ainda nos anos de 1980, Kliksberg (1988) também já alertava para a necessidade de um novo perfil para o gestor público diante do contexto em transformação, tal como descrito anteriormente. Para o autor, o gestor dos anos de 1990, que poria fim ao modelo weberiano, deveria possuir o seguinte perfil: desenvolvimento de habilidades criativas e de relacionamento; domínio do método científico e capacidade metodológica para compreender, de modo articulado e rigoroso, a realidade das organizações; domínio atualizado em ciências que expliquem o contexto organizacional, tais como história econômica e social, economia e sociologia; preparação tecnológica; capacidade de gerar identificação organizacional e participação; inteligência críticocriativa, que permite a combinação de variáveis diversas e complexas para a solução de problemas cada vez mais complexos. O desenvolvimento de tal perfil exigiria uma preparação não-convencional por parte dos gestores (KLIKSBERG, 1994), levando-os a um novo patamar de excelência. No caso específico da administração pública, o gestor poderia levar a uma maior eficácia e excelência das organizações públicas.

Atualmente, o Poder Público vem sendo cobrado pela sociedade em termos de resultados. Newcomer (1999, p. 6), por exemplo, destaca que há questões básicas que os cidadãos e seus representantes eleitos colocam aos seus governos:

- "Os gerentes públicos devem proporcionar provas dos resultados de seus programas, o que é conhecido como accountability for performance (responsabilização pelo desempenho);

- O governo deve fazer contratos com entidades privadas ou sem fins lucrativos para a prestação de alguns serviços, o que é conhecido como terceirização ou privatização;

- O governo deve reduzir sua força de trabalho e passar a contratar um maior número de trabalhadores temporários, e portanto, menos onerosos, dando-se a esse fato o nome de enxugamento;

- Deve-se atribuir aos cidadãos, também chamados de clientes, um papel mais importante na tomada de decisões governamentais, envolvendo uma gama de atividades que vai da atribuição de prioridades a objetivos governamentais à definição de regulamentações aplicáveis em empresas privadas".

Nessa linha de ação, o governo Fernando Henrique Cardoso, em seu primeiro mandato, foi emblemático ao instituir o Ministério da Administração Federal e Reforma do Estado (MARE), com o objetivo de promover, conforme seu nome indica, a reforma do Estado e, consequentemente, da gestão pública, na direção da chamada "gestão pública gerencial", entendida como sendo orientada para o cidadão e que visa atender suas necessidades, por meio de descentralização e delegação de autoridade e de responsabilidade ao gestor 
público, aferindo-se o desempenho mediante indicadores acordados e definidos em contrato (BRESSER PEREIRA, 1996), o chamado "contrato de gestão".

O modelo gerencial para a administração pública pressupõe que o gestor público, dotado de uma racionalidade gerencial, poderia dar conta de resolver todos os problemas que lhe são colocados, uma vez que seria treinado para isolar as atividades umas das outras e aquelas da autoridade direta e para avaliar o desempenho dos serviços e das atividades governamentais por meio de indicadores objetivos. Tal visão não é compartilhada por Mintzberg (1998), que percebe as atividades do governo como complexas, interconectadas e, muitas vezes, ambíguas. Uma racionalidade puramente econômica ou gerencial não seria apropriada para se gerir o setor público e medir seus resultados, a não ser em situações muito específicas, como a operação de uma loteria.

No contexto da administração pública atual, alguns desafios são colocados aos gestores (SCHWELLA, 2005), tais como a globalização, a complexidade dos problemas, as desigualdades econômicas e sociais, a diversidade, a adoção de uma boa governança, a erosão da confiança, dentre outros. Para tanto, o autor sugere que o gestor público desenvolva habilidades de liderança para o desempenho eficaz de suas atividades diante dos desafios que lhe são colocados.

Longo (2003) também defende que deve haver o desenvolvimento de dirigentes públicos, cujas competências deverão ser diversas e baseadas num conjunto de atributos, tais como motivos, traços de caráter, conceito de si mesmo, atitudes ou valores, habilidades e capacidades cognitivas e de conduta. Além disso, o contexto da administração pública deve ser preparado para tanto, incluindo uma mudança cultural. Tal mudança cultural implicará, inclusive, o desenvolvimento de uma identidade coletiva reconhecível. Para tanto,

[...] parece necessária a existência de massa crítica suficiente de pessoas que se percebam como dirigentes públicos, construindo essa percepção a partir de modelo comum de funções de direção e de acordo com os traços básicos descritos, bem como a partir de um conjunto de competências profissionais distintivas, coerentes com aquele modelo (LONGO, 2003, p. 28).

Newcomer (1999) concorda com Mintzberg (1998), na medida em que considera que enviar os gestores públicos para escolas de administração para aprenderem técnicas voltadas às empresas privadas não funcionaria. Seu argumento, tal como Mintzberg (1998), é que estratégias de desempenho, contabilidade e custos, por exemplo, não são a mesma coisa nos setores público e privado. No entanto, segundo a autora, os gestores públicos têm de ser bilíngues, ou seja, "fluentes na terminologia usada pelos gerentes do setor privado, pelos especialistas em informática e na linguagem política e governamental utilizada por seus muitos patrões políticos" (NEWCOMER, 1999, p. 11). A autora sugere os conhecimentos e as habilidades que os gestores precisam desenvolver, conforme a figura 1. 
Figura 1

Conhecimentos e habilidades necessários ao gestor público, segundo Newcomer

\begin{tabular}{|c|c|}
\hline Conhecimentos de & Habilidades em \\
\hline 1. Direito constitucional & 1. Planejamento estratégico \\
\hline 2. Ética & 2. Mensuração de desempenho \\
\hline 3. A ética do serviço público & 3. Monitoramento de contratos \\
\hline $\begin{array}{l}\text { 4. Direito processual em gestão de recursos } \\
\text { humanos e nas áreas substantivas } \\
\text { relevantes }\end{array}$ & $\begin{array}{l}\text { 4. Utilização de dados sobre desempenho e } \\
\text { avaliação para melhorar programas }\end{array}$ \\
\hline $\begin{array}{l}\text { 5. Procedimentos de políticas de alocação de } \\
\text { recursos }\end{array}$ & $\begin{array}{l}\text { 5. Prestação de contas sobre desempenho e } \\
\text { dados }\end{array}$ \\
\hline 6. Instituições governamentais e econômicas & $\begin{array}{l}\text { 6. Administração financeira, inclusive atividades } \\
\text { de cálculo de custos }\end{array}$ \\
\hline $\begin{array}{l}\text { 7. Direito internacional } \\
\text { D }\end{array}$ & 7. Envolvimento dos cidadãos \\
\hline 8. Política de grupos de interesse & $\begin{array}{l}\text { 8. Solução de conflitos e negociação } \\
\text { 9. Criação de consenso }\end{array}$ \\
\hline 9. Modelagem econômica & 10. Motivação e animação de pessoal \\
\hline & $\begin{array}{l}\text { 11. Análise de problemas, inclusive técnicas de } \\
\text { estatística e de custo-benefício }\end{array}$ \\
\hline
\end{tabular}

Fonte: Newcomer (1999, p. 12)

Atualmente, no Brasil, Amaral (2006) aponta para um conjunto de competências que o dirigente deve possuir, adequadas aos objetivos institucionais. Sua proposta é baseada no chamado modelo de gestão por competências, que "significa olhar para o trabalho por uma lente que combina os conhecimentos, o saberfazer, a experiência e os comportamentos exercidos em contexto específico. $\mathrm{O}$ foco não mais repousa sobre a atribuição formal de um posto de trabalho" (AMARAL, 2006, p. 554). Para a autora, este modelo implica maior responsabilidade dos dirigentes, pois envolve lidar com a incerteza, correr riscos, aprender coletivamente e questionar-se. O coletivo é prioritário, o que significa afirmar que a "grande referência para a ação coletiva não é a descrição das atribuições do órgão, mas a visão compartilhada, o sentido comum do trabalho." (AMARAL, 2006, p. 557)

As competências, que são reveladas quando as pessoas agem diante das situações profissionais com as quais se deparam e servem como ligação entre as condutas individuais e a estratégia da organização, podem ser entendidas como combinações sinérgicas de conhecimentos, habilidades e atitudes, expressas pelo desempenho profissional em determinado contexto ou em determinada estratégia organizacional. As competências geram um desempenho profissional que, por sua vez, é expresso pelos comportamentos manifestos e pelas consequências de tais comportamentos, em termos de realizações e resultados (BRANDÃO e BAHRY, 2005). 
A partir do modelo de gestão de competências, Amaral (2006) aponta a experiência de alguns países para definir o caso brasileiro. A figura 2 resume as principais competências para os dirigentes norte-americanos, ingleses e canadenses, segundo a autora.

Figura 2

Competências para os dirigentes americanos, ingleses e canadenses

\begin{tabular}{|c|c|}
\hline Países & Competências prescritas \\
\hline $\begin{array}{l}\text { Estados } \\
\text { Unidos }\end{array}$ & $\begin{array}{l}\text { - Capacidade de liderar mudanças; } \\
\text { - Capacidade de liderar pessoas; } \\
\text { - } \quad \text { Orientação para resultados; } \\
\text { - Conhecimentos em gestão de pessoas, capacidade de gestão } \\
\text { - } \quad \text { Cinanceira e gestão de tecnologia de informação; } \\
\text { - }\end{array}$ \\
\hline $\begin{array}{l}\text { Reino } \\
\text { Unido }\end{array}$ & $\begin{array}{l}\text { - } \quad \text { Criar e comunicar visão de futuro; } \\
\text { - } \text { - Liderivar e desenvolver pessoas para obter alto desempenho; } \\
\text { - Empregar a experiência e novas ideias para melhorar resultados; } \\
\text { - Pensamento estratégico para atingir objetivos. }\end{array}$ \\
\hline Canadá & $\begin{array}{l}\text { - Competências intelectuais, que se referem à capacidade cognitiva e à } \\
\text { criatividade; o desenvolvimento futuro de competências, que se } \\
\text { traduz na visão do futuro; } \\
\text { - Competências de gestão, entre as quais se encontram a gestão-ação, } \\
\text { a consciência organizacional, o trabalho em equipe e o } \\
\text { desenvolvimento de parcerias. } \\
\text { - Competências relacionais (relações interpessoais e comunicação) } \\
\text { - Competências individuais (resistência ao estresse, ética e valores, } \\
\text { personalidade, flexibilidade comportamental e autoconfiança). }\end{array}$ \\
\hline
\end{tabular}

Fonte: Baseado em Amaral (2006).

Tomando-se como referência tais modelos, e em particular o canadense, a ENAP (Escola Nacional de Administração Pública) estruturou um programa de desenvolvimento para dirigentes públicos brasileiros, no âmbito da Rede Nacional de Escolas de Governo (criada em 2003), calcado no desenvolvimento das competências prescritas na figura 3 , a seguir (AMARAL, 2006). 
Figura 3

Competências do dirigente público brasileiro

\begin{tabular}{|c|c|}
\hline Classes & Competências \\
\hline Fundamentais/genéricas & $\begin{array}{l}\text { - Comprometimento com o serviço público } \\
\text { - Trabalho em equipe } \\
\text { - Flexibilidade } \\
\text { - Sensibilidade social } \\
\text { - Negociação } \\
\text { - Comunicação }\end{array}$ \\
\hline Organizacionais & $\begin{array}{l}\text { - Conhecimento da administração pública } \\
\text { - Comacidade de aprender } \\
\text { - Negociação } \\
\text { - Planejamento educacional } \\
\text { - Metodologias de ensino } \\
\text { - Prospecção de conhecimentos em gestão pública } \\
\text { - Gestão de escola de governo } \\
\text { - Conhecimentos de ferramentas de Tl e sistemas governamentais }\end{array}$ \\
\hline Gerenciais & $\begin{array}{l}\text { - Liderança inspiradora } \\
\text { - Senso de direção } \\
\text { - Comprometimento } \\
\text { - Gestão integrada e estratégica de recursos (capacidade de } \\
\text { - } \text { - Visanejamento) } \\
\text { - Capacidade de análise e síntese } \\
\text { - Implementação equilibrada das políticas públicas } \\
\text { - Gestão de pessoas }\end{array}$ \\
\hline Pessoais e interpessoais & $\begin{array}{l}\text { - Expansão contínua das fronteiras pessoais } \\
\text { - Capacidade de articulação } \\
\text { - Resolução de problemas } \\
\text { - Iniciativa } \\
\text { - Cooperação }\end{array}$ \\
\hline
\end{tabular}

Fonte: Amaral (2006, p. 558) 
Ressalta-se que, de uma forma geral, os diversos autores e especialistas apontam a necessidade de se mudar o perfil da administração pública, no mundo e no país. Para tanto, as reformas incluem necessariamente uma mudança no perfil do gestor público para atender aos desafios que lhe são impostos. É no bojo desta discussão que emerge a questão do gestor universitário.

\section{A Universidade: Contexto de Atuação e Competência Gerencial}

Embora sejam bastante comuns estudos e publicações sobre a gestão universitária em geral, o mesmo não ocorre com relação ao gestor universitário, em particular. No entanto, num dos trabalhos emblemáticos sobre a instituição universitária contemporânea, Clark Kerr (1982) entende o reitor como um personagem de muitas faces, no sentido de que deve olhar para diversas direções, evitando "dar as costas" a qualquer grupo importante.

Para Kerr (1982), o reitor deve possuir um conjunto extenso de características:

Espera-se do reitor da universidade, nos Estados Unidos, que seja um amigo dos estudantes, um colega dos docentes, um excelente confrade nas associações de ex-alunos, um administrador idôneo para com os curadores, um bom orador para o público, um regateador astuto com as fundações e agências federais, um político com os deputados estaduais, um amigo da indústria, do trabalho e da agricultura, um diplomata persuasivo com os doadores, um paladino da educação em geral, um protetor das profissões (particularmente direito e medicina), um porta-voz para a imprensa, um erudito na expressão da palavra, um funcionário público em níveis estadual e nacional, um amante da ópera e igualmente de futebol, um ser humano decente, um bom marido e pai, um membro ativo de sua igreja. Acima de tudo, deve deleitar-se em viajar de avião, fazer refeições em público e comparecer a cerimônias públicas. (KERR, 1982, p. 37)

Evidentemente, não se trata de um perfil formal, mas de um conjunto de expectativas nutridas por uma comunidade em relação ao indivíduo que assume uma função de tanto prestígio social. Como o próprio autor admite, nenhum indivíduo é capaz de possuir todas as características e alguns outros sequer possuem algumas delas. No entanto, isso não elimina as expectativas (embora as frustre na prática), as quais, entretanto, sempre se manifestam à época das eleições para o cargo de reitor nas universidades brasileiras, por exemplo. Além de se evidenciarem discussões acerca dos projetos e dos planos de governo, a comunidade também discute e evidencia as características pessoais de cada candidato, e não apenas o seu currículo profissional. No entanto, o próprio Kerr (1982) adverte que uma das questões centrais é saber se o reitor será um líder ou um burocrata. Para o autor, o reitor é "líder, educador, criador, iniciador, manipulador de poder, perquiridor; e é também burocrata, zelador, herdeiro, conciliador, persuasor, 'bitolador'. Mas acima de tudo é um mediador" (KERR, 1982, p. 41).

Para Bennis (1999), não existe um tipo ou uma personalidade de reitor, ou uma qualidade, característica e estilo únicos, ou, mesmo, um bom currículo que garanta a capacidade de um reitor. Para o autor, existem vários enfoques bem-sucedidos no gerenciamento de universidades. Além disso recomenda que uma universidade deve estabelecer sua metáfora específica ou imagem coletiva do que é a universidade ou o que ela poderia ser e, a partir daí, decidir pelo tipo de reitor de que necessita. Em outras palavras, pode-se dizer que o autor está sugerindo que a instituição universitária estabeleça sua identidade organizacional de modo a encontrar um gestor que se identifique com ela.

No Brasil, Finger (1986) entende que uma universidade não pode ser gerenciada como uma empresa. Diante disso, espera que o reitor desempenhe os papéis de educador, líder educacional, representante da universidade perante o público em geral, coordenador-geral das atividades e líder administrativo. Tal como 
Finger (1986), Cunha (1999) também entende que a universidade não pode e nem deve ser gerenciada como uma empresa ou, tampouco, por exemplo, pelos métodos da "qualidade total" empresarial, o que não implica não considerar a qualidade como um valor central, desde que se esclareça o que qualidade significa na instituição (TRIGUEIRO, 1999).

Uma universidade é povoada por diversos centros de poder (KERR, 1982) que de algum modo precisam ser conciliados. Nesse sentido, Trigueiro (1999, p. 110) defende a elaboração de um projeto institucional, que significa "o conjunto dos interesses, necessidades, demandas, objetivos, diretrizes e ações planejadas pela universidade, capaz de dar sentido, coesão, fundamentação ao próprio desenvolvimento da organização, auxiliando na competição externa e incrementando a integração interna".

Sob a perspectiva política, a gestão pode ser compreendida como aquela que se caracteriza (REED, 1997):

como um processo social direcionado para a regulação do conflito entre grupos de interesse, num meio caracterizado por incertezas sobre o desempenho organizacional;

como um sistema político em que uma pluralidade de grupos concorre entre si ou entre alianças que normalmente entram em conflito a propósito de decisões quanto às configurações organizacionais, resolvendo o desacordo através do exercício do poder;

como um sistema em que o aumento do conhecimento dos gestores sobre a sutileza e onipresença dos processos políticos por meio dos quais se negocia a mudança organizacional, bem como sua sensibilidade aos mesmos, pode facilitar a introdução de formas de controle mais eficazes, à medida que tal permite uma apreciação mais realista dos obstáculos que provavelmente se colocam à consecução dos resultados desejados.

Essa situação a que o reitor (e, de resto, todos os membros da universidade) está submetido se deve, em parte, à própria natureza da instituição. Em princípio, ela é o locus de geração e transmissão de conhecimento; logo, portadora de um espaço de liberdade, de criação intelectual livre e de inovação. Por outro lado, a universidade é também uma burocracia, e como tal, também portadora de suas mazelas e emperramentos. Assim, considerando-se a universidade como um conjunto de práticas racionalizadas, pergunta-se: como conciliar rotina e inovação? (NUSSENZVEIG, 2004, p. 151).

Neste contexto está o reitor, que deve ser capaz de conciliar dois aspectos a princípio contraditórios (rotina X inovação). Observa-se que na estrutura universitária a maior parte das decisões se dá de forma colegiada, o que, de certo modo, dilui a responsabilidade individual, ou seja, a do reitor e de seus pares gestores. Além das características intrínsecas à instituição universitária, alguns observadores apontam para a vigência de uma crise profunda, irredutível a uma causa única. Ao contrário, a universidade parece enfrentar uma crise de natureza tríplice, pelo menos na visão de Santos (2003, 2004): de hegemonia, de legitimidade e institucional.

Segundo Santos (2003), a crise de hegemonia resulta das contradições entre as funções clássicas da universidade e aquelas a ela atribuídas no decorrer do século XX: alta cultura para a elite versus produção de padrões culturais médios e de conhecimentos instrumentais para a formação de mão de obra. A crise de legitimidade é observada à medida que se torna visível socialmente a falência dos objetivos coletivos. No caso da universidade, observa-se a contradição entre a hierarquização dos saberes especializados por meio das restrições de acesso e do credenciamento das competências, de um lado, e as pressões sociais e políticas de democratização da instituição e da igualdade de oportunidades para os filhos das classes menos favorecidas, de outro. A crise institucional, por fim, ocorre à medida que a especificidade administrativa da instituição é posta em xeque e se lhe impõem outros modelos tidos como mais eficientes, baseados em critérios de eficácia de natureza empresarial ou de responsabilidade social (SANTOS, 2003, 2004). 
Portanto, como se pode perceber, o reitor (e, por conseguinte, os demais gestores universitários) está inserido numa instituição que ele representa e gerencia, a qual está em crise, sendo-lhe exigida, como um tipo particular de gestor público, uma forma de atuação diferenciada.

\section{Metodologia}

Considerando-se que o tipo de problema ou fenômeno a ser investigado aponta para o tipo de metodologia a ser adotada (ALVESSON e SKÖLDBERG, 2000), a análise qualitativa se mostrou adequada. Nos dizeres de Silverman (1993, p. 2), "metodologias não são verdadeiras nem falsas, elas são apenas mais ou menos úteis". Embora possam assumir diversas conotações (DENZIN e LINCOLN, 1994), a pesquisa qualitativa possui uma abordagem basicamente compreensiva, pois visa "apreender e explicitar o sentido da atividade social individual e coletiva enquanto realização de uma intenção" (BRUYNE, HERMAN e SCHOUTHEETE, 1991, p. 139). Ao mesmo tempo, empenha-se na investigação de um fenômeno não subsumido por uma lei geral, mas apreendido enquanto elemento original e específico (BRUYNE, HERMAN e SCHOUTHEETE, 1991). Nos termos de Chanlat (2000), não se busca "atingir a verdade social em sua objetividade quimérica, mas em sua verdade vivenciada" (CHANLAT, 2000, p. 26).

A pesquisa pode ser caracterizada como descritiva analítica, utilizando de procedimentos sistemáticos e objetivos de descrição do conteúdo dos discursos (BARDIN, 1977). Também pode ser considerada como estudo de caso, no sentido de que se trata de gestores das universidades federais localizadas no estado de Minas Gerais, em relação ao conjunto das universidades públicas federais brasileiras. Seu rigor científico apoia-se em conceitos e questões de pesquisa, guiados por uma construção teórica que serviu de princípio diretor para a coleta de dados e como suporte para a análise dos mesmos, como recomendam Bruyne, Herman e Schoutheete (1991). Nesse sentido, a escolha de universidades mineiras pode não representar estatisticamente a população, mas é capaz de representar a relevância do fenômeno que se pretende estudar (FLICK, 2009).

Os sujeitos da pesquisa - representantes da alta administração universitária - foram os reitores, vice-reitores e dois pró-reitores de oito universidades federais instaladas no estado de Minas Gerais, totalizando trinta e dois gestores. A coleta dos dados primários foi feita por meio da entrevista episódica (FLICK, 2003) e semiestruturada, a qual parte de questões elaboradas previamente e apoiadas nos objetivos propostos e em teorias pertinentes à pesquisa, oferecendo amplo campo para interrogativas a partir da interação com o entrevistado (TRIVIÑOS, 1987), permitindo-lhe grande liberdade de abordagem ao tema (MINAYO, 2002). Todas as entrevistas foram gravadas e transcritas. A finalidade básica, para fins deste artigo, é identificar, a partir do ponto de vista dos sujeitos, quais são as competências desejadas para o ocupante do cargo de reitor em suas universidades, de modo a confrontar com as prescrições feitas para o gestor público em geral, e para o reitor em particular. É nesse sentido que a pesquisa qualitativa e seus métodos partem da perspectiva ou das ações do sujeito estudado (ALVESSON e SKÖLDBERG, 2000).

Para a análise dos dados primários, utilizou-se basicamente da análise temática, que consiste em descobrir os "núcleos de sentido" que compõem a fala dos entrevistados. (BARDIN, 1977). Essa técnica privilegia, portanto, o conteúdo dos relatos, sendo estes confrontados com os conceitos utilizados, permitindo-se avançar no conhecimento acerca da realidade específica dos gestores da alta administração de universidades localizadas em Minas Gerais. 


\section{Os Gestores em suas Universidades: Contexto e Competências}

\section{O contexto institucional de atuação dos gestores}

A Lei ${ }^{\circ}$ 9.394, de 20 de dezembro de 1996, que estabelece as diretrizes e bases da educação nacional (LDBEN), em seu artigo 56, assegura que "as instituições públicas de educação superior obedecerão ao princípio da gestão democrática, assegurada a existência de órgãos colegiados deliberativos, de que participarão os segmentos da comunidade institucional, local e regional". Em seu parágrafo único, garante que "os docentes ocuparão setenta por cento dos assentos em cada órgão colegiado e comissão, inclusive nos que tratarem da elaboração e modificações estatutárias e regimentais, bem como da escolha de dirigentes." Além disso, a referida lei exige que cada instituição estabeleça seus estatutos e regimentos, os quais preveem dentre outras matérias, as atribuições que competem aos seus reitores. No entanto, não prescrevem as qualificações necessárias.

As oito universidades às quais pertencem os entrevistados estão localizadas no estado de Minas Gerais, e por serem autarquias federais, possuem personalidade jurídica de direito público, gozando de autonomia administrativa, acadêmica (didático-científica) e de gestão financeira. Suas estruturas organizacionais, embora peculiares sob certos aspectos, são semelhantes, na medida em que possuem uma estrutura decisória colegiada, organizada em forma de assembleias e/ou conselhos, em vários níveis hierárquicos. Em todas as instituições, a instância máxima é o chamado Conselho Superior ou Conselho Universitário, sempre presidido pelo reitor.

O cargo de Reitor somente pode ser ocupado por um professor do quadro permanente, desde que atenda ao disposto no artigo 16, inciso I, da Lei 5.540/68, alterada pela Lei 9.192/95: "o Reitor e o Vice-Reitor de universidade federal serão nomeados pelo Presidente da República e escolhidos entre professores dos dois níveis mais elevados da carreira ou que possuam título de doutor, cujos nomes figurem em listas tríplices organizadas pelo respectivo colegiado máximo, ou outro colegiado que o englobe, instituído especificamente para este fim, sendo a votação uninominal". Segundo a legislação, é permitido que a instituição faça uma consulta à comunidade acadêmica. Entretanto, a decisão final quanto à nomeação reside na Presidência da República.

As instituições compõem o chamado Sistema Federal de Ensino, e estão vinculadas ao Ministério da Educação, particularmente à Secretaria de Educação Superior, cujas funções, previstas na LDB, envolvem o planejamento, a orientação, a coordenação e a supervisão do processo de formulação e implementação da Política Nacional de Educação Superior. Inclui, também, a manutenção, supervisão e desenvolvimento das instituições federais de ensino superior (IFES) e a supervisão das instituições privadas de educação superior.

\section{A concepção de universidade, segundo os entrevistados}

Para subsidiar a análise das competências atribuídas aos reitores, pressupõe-se que sua ação é condicionada pela concepção que têm acerca do papel da universidade. Segundo os entrevistados, basicamente em sua totalidade, as universidades públicas são grandes responsáveis pelo desenvolvimento econômico e social do país. Seja por meio de geração de conhecimento útil para a sociedade, seja porque prepara pessoas com um nível de qualidade superior. Para diversos entrevistados, elas representam a principal referência de qualidade no ensino, pesquisa e extensão. Nesse sentido, ressaltam tanto as universidades mantidas pela União quanto aquelas mantidas pelos estados da federação, notadamente as de São Paulo.

Os depoimentos ressaltam algumas questões centrais, como o desenvolvimento socioeconômico 
eu acho que as universidades públicas, pelo papel que elas têm na construção da nacionalidade e especialmente na condição que elas influem de ser, a meu ver, a grande alavanca no desenvolvimento econômico brasileiro no curso dessa recente evolução do capitalismo. Elas têm um papel ímpar, um papel inestimável. R1.

Eu acho que a história da universidade federal no Brasil, ela tem a ver com o próprio desenvolvimento socioeconômico do país, eu acho que, se a gente fizer uma relação entre o salto que o Brasil deu em termos de desenvolvimento econômico, tem a ver com as ações das universidades federais. R5

Em termos da qualidade inerente às instituições públicas, os gestores afirmam categoricamente:

eu acho que o conceito de fato de universidade, ele é muito bem exercido pelas universidades públicas federais, são ainda a grande referência em qualidade. R2

Reiterando a qualidade, um dos reitores afirma que a instituição é digna de confiança:

eu acho que se tem uma coisa que a população pode confiar e apoiar é o sistema universitário público, federal e estadual, [...] então, eu acho que é um sistema que se desenvolveu porque teve apoio dos vários governos, independente de ideologias e foi uma coisa que deu certo, então eu sou otimista, eu acho que estamos no caminho, é claro que sempre tem muito espaço para melhorar, mas nós estamos no caminho. R3.

No entanto, um dos reitores ressalta a possível deficiência na sua finalidade de "extensão", como pode ser observado no depoimento a seguir:

a universidade nessa função social ela ainda está muito longe da comunidade e ela pode exercer uma série de atividades importantes, isso porque eu defino universidade, de uma forma um pouco diferente do que as pessoas imaginam que ela é, eu acho que a universidade é parte integrante da sociedade [...] o que ela precisa é responder estrategicamente aos interesses da sociedade, ela tem que dar resposta... R4.

Por fim, destaca-se que a formação do indivíduo deve contribuir para a sociedade, e não apenas para seu próprio bem-estar:

temos que formar [...] agentes de mudança, agentes de mudança da sociedade, ora se se cria uma universidade para resolver um problema porque o sistema, a economia ia mal, logicamente então a sociedade começa a sofrer os reflexos de uma economia problemática, e se nós temos que desenvolver economicamente e socialmente uma região, uma comunidade, logicamente que nós temos que pensar que as pessoas que nós vamos colocar no mercado sejam agentes de mudança, então eu tenho sempre comentado que nós não podemos simplesmente formar pessoas em atendimento ao mercado, nossos profissionais estarão no futuro até mesmo alterando o perfil sociológico da comunidade, alterando então as próprias necessidades da comunidade ... R8.

Assim, percebe-se que a concepção do papel da instituição é, basicamente, uma unanimidade entre os entrevistados, embora possam até discordar sobre ações ou políticas específicas. Como reitores, tal concepção de universidade implica exercer um papel estratégico, que deve estar alinhado aos interesses da sociedade em sentido amplo. Entretanto, implica, também, ser capaz de organizar internamente os diversos 
envolvidos na realização desse papel. Para tanto, algumas competências são desejadas, como se verá, a seguir.

\section{As competências gerenciais dos reitores}

Os reitores se definem e são definidos pelos pares basicamente como políticos e gestores, embora atribuam um peso significativamente maior para a primeira definição. A partir dessa identificação, os entrevistados (reitores, vice-reitores e pró-reitores) apontam como competência central do reitor a capacidade política, tal como pode ser observado nas tabelas 1,2 e 3 .

Dos oito reitores entrevistados, quatro $(50 \%)$ mencionaram a expressão "habilidade política" (Tabela 1) como elemento decisivo para o desempenho de suas funções, embora os demais a tenham mencionado de forma indireta, ao ressaltarem atributos tais como "representantes", "negociadores", "líder de um grupo".

[...]numa empresa o melhor caminho é aquele, eu analisei, determinei que é por aqui e todo mundo tem que ir, mas numa universidade você tem que fazer o consenso e isso está longe de ser uma coisa simples". R3

Tem duas cadeias no poder dentro da universidade, e não é simples você compatibilizar as duas, né? O poder derivado da hierarquia [...] o reitor, o vice-reitor, os diretores, os chefes, os coordenadores e tal, e tem a cadeia do poder derivada do conhecimento. $\mathrm{O}$ reitor não tem poder nessa cadeia [...] Então, para você compatibilizar essa questão da política interna [...] é preciso ser um daqueles que corre, porque quem corre por gosto não cansa. Se não for assim, se não estiver correndo por gosto, então vai ser preciso ter um certo espírito de abnegação". R8

Observe-se que dois apontaram a capacidade de se perceber a pluralidade de ideias e visões que habitam a instituição, de modo a se gerenciá-la de modo adequado. Ressaltam, ainda, competências relacionadas à função gerencial, como a capacidade de se ter uma visão clara do futuro (Tab. 1).

Tabela 1

\section{Competências desejáveis aos reitores segundo os reitores entrevistados}

\begin{tabular}{|l|c|c|}
\hline \multirow{2}{*}{ Respostas } & \multicolumn{2}{c|}{ Frequência } \\
\cline { 2 - 3 } & Absoluta & Relativa \\
\hline Ter habilidade política & 4 & $50,0 \%$ \\
\hline $\begin{array}{l}\text { Ter percepção de liberdade/pluralidade de } \\
\text { ideias }\end{array}$ & 2 & $25,0 \%$ \\
\hline Ter uma visão do futuro clara & 2 & $25,0 \%$ \\
\hline
\end{tabular}

Fonte: Elaborada pelo autor.

Nota: Aos entrevistados foi permitido fornecer mais de uma resposta. 
Dentre os oito vice-reitores, seis (75\%) apontaram claramente a "capacidade política" como competência central para ser reitor, enquanto metade deles aponta a necessidade de se deter conhecimentos sobre administração. Ressaltam, também, a capacidade acadêmica do professor que ocupa o cargo de reitor (Tab. 2).

Tabela 2

\section{Competências desejáveis aos reitores segundo os vice-reitores entrevistados}

\begin{tabular}{|l|c|c|}
\hline \multirow{2}{*}{ Respostas } & \multicolumn{2}{|c|}{ Frequência } \\
\cline { 2 - 3 } & Absoluta & Relativa \\
\hline Ter capacidade política & 6 & $75,0 \%$ \\
\hline Ter um certo conhecimento de administração & 4 & $50,0 \%$ \\
\hline Ter capacidade acadêmica & 3 & $37,5 \%$ \\
\hline
\end{tabular}

Fonte: Elaborada pelo autor.

Nota: A frequência ultrapassa $100 \%$ porque os entrevistados forneceram mais de uma resposta.

O conhecimento em administração é evidenciado por um dos vice-reitores como central para uma gestão eficaz, criticando o fato de que, em sua opinião, elegem-se os indivíduos por outras razões, que não a competência gerencial.

deve ter noções mínimas de administração, confesso que (...) estamos aprendendo (...) Então, nós não temos realmente o preparo (...) mínimo, adequado para enfrentar esse desafio. No entanto, isso tem sido prática em quase todas as universidades, elegem-se pessoas e não se elege o administrador. Não sei se é o melhor modelo, mas é o modelo que está aí (...) eu acredito que eu poderia ter muito mais sucesso se eu já chegasse com um preparo maior. (V4)

Seu depoimento implica considerar que a candidatura ao cargo deveria ocorrer desde que o indivíduo possuísse tal competência. Até porque, ao que parece, a capacidade administrativa estaria relacionada mais à rotina burocrática e orçamentária, como declara um dos vice-reitores:

Eu acho que o reitor ideal precisaria menos da capacidade administrativa, se a universidade funcionasse com verbas, se ela funcionasse com um orçamento menos marcado pela incerteza, algo mais definido, essa parte administrativa andaria mais ou menos sozinha, então você construiria a grande visão estratégica e esta visão definiria as prioridades dentro do orçamento que você tem, mas como há um grau de incerteza muito grande em relação às condições materiais, e aí nós não estamos falando só de dinheiro mas também de recursos humanos... (V5).

Dos dezesseis pró-reitores entrevistados, a maioria absoluta (75\%) destacou a capacidade de liderar politicamente a instituição. Apontaram, também de forma bem evidente, a necessidade de se ter uma carreira na universidade. A concepção de carreira se traduz no entendimento de que o reitor deve ter ocupado outros cargos gerenciais, bem como entender a dinâmica e papel da instituição. Assim, ressaltam o acúmulo de experiências como um tipo de competência, implicando o desenvolvimento e a aprendizagem na função. 
Embora em menor quantidade, os pró-reitores indicaram a capacidade de liderar gerencialmente, o que implica a capacidade de liderar pessoas em suas atividades.

Tabela 3

Competências desejáveis aos reitores segundo os pró-reitores entrevistados

\begin{tabular}{|l|c|c|}
\hline \multicolumn{1}{|c|}{ Respostas } & \multicolumn{2}{c|}{ Frequência } \\
\cline { 2 - 3 } & Absoluta & Relativa \\
\hline Ter liderança política & 12 & $75,0 \%$ \\
\hline Ter uma carreira na universidade & 10 & $62,5 \%$ \\
\hline Ter liderança gerencial & 4 & $25,0 \%$ \\
\hline
\end{tabular}

Fonte: Elaborada pelo autor.

Nota: A frequência ultrapassa $100 \%$ porque os entrevistados forneceram mais de uma resposta.

Ao manifestar a capacidade política, pelo menos um dos pró-reitores manifestou a ideia de que o reitor, uma vez eleito, deveria "esquecer" os conflitos e governar como se fosse o representante de uma única voz coletiva, mas que isso não ocorre por conta de grupos ou indivíduos com interesses particulares.

Eu acho que a primeira declaração que o reitor tem que fazer é a seguinte: gente, eu sou o reitor de todos, que venham a mim todos e vai ser igual. Mas aí tem a turma que diz "não, eu te apoiei porque eu quero, agora você me dê um tratamento diferenciado.” (P27)

Observe-se que outros pró-reitores também insinuaram que a dimensão política, embora necessária, não deveria ser empecilho para sua gestão. Em suas visões, o reitor deveria ser capaz de se portar como uma espécie de estadista, direcionado para um objetivo maior e para o bem comum, como sugerem os depoimentos abaixo.

O Reitor é mais uma "Rainha da Inglaterra" (P4).

Eu acho que o Reitor tem que ser magnânimo... é por isso que ele é magnífico, né? (P2).

A análise dos depoimentos evidencia claramente a identificação das competências distintivas que os indivíduos no cargo devem possuir.

\section{As competências prescritas para o gestor público e o caso dos reitores pesquisados}

Tomando-se as competências prescritas para o gestor público em geral como elementos de comparação, percebem-se algumas peculiaridades dignas de destaque quanto às competências desejadas para os reitores pesquisados (Figura 4, a seguir). 
As competências apontadas por Amaral (2006), anteriormente definidas, são confrontadas com as competências dos reitores das universidades mineiras estudadas. A comparação permite assinalar que a competência política do reitor é a principal competência genérica e diferença para os demais gestores públicos. Nesse sentido, ele deve ser capaz de representar os diversos interesses da instituição, sobretudo em instâncias externas à instituição, como a ANDIFES e o MEC. É possível que essa diferença ocorra pelo fato de que o reitor é "eleito" internamente pelos pares, enquanto outros gestores públicos são nomeados (como presidentes ou diretores de agências, por exemplo).

A gestão universitária implica a negociação permanente de diversos interesses, oriundos de unidades diversas, de grupos diferenciados. Tais interesses circulam numa teia complexa de relacionamentos, acarretando a formação de grupos de interesses específicos e articulados. A rede de relacionamentos - rede política - pode ser entendida como frouxamente articulada, posto que as relações de poder são relativamente instáveis. Tal instabilidade se deve, em parte, ao grau de autonomia dos docentes em particular, que dependem muito pouco da reitoria para realizarem suas atividades.

Dentre as competências organizacionais, as diferenças são significativas. Destaca-se, por exemplo, a capacidade de captar oportunidades para a instituição. Tal competência está associada à chamada visão empreendedora e reflete a concepção de que uma universidade deva ser concebida como um tipo de organização atenta ao seu "mercado". Ressalta-se, também, a competência e a liderança acadêmica em suas áreas de atuação, que funcionam, na prática, como legitimadoras da função gerencial.

As competências gerenciais dos gestores públicos e reitores, por sua vez, aproximam-se. Aos gestores universitários compete liderar gerencialmente suas instituições em direção a um futuro visualizado, decidindo-se pelas questões prioritárias (de acordo com as oportunidades de mercado), e gerenciando os possíveis conflitos que surgirem. O mesmo se espera do gestor público em geral, na medida em que seu comprometimento e capacidade de liderança inspirariam as pessoas à sua volta a alcançar os objetivos projetados para o futuro, graças à sua mente aberta e visionária.

Por fim, as competências pessoais e interpessoais coincidem no que diz respeito à capacidade de articulação e de cooperação. Como alguém que concebe a instituição como povoada de diversos interesses, é necessário que seja alguém paciente, tolerante, ético e confiável.

Figura 4

\section{Competências do dirigente público em geral x competências dos reitores}

\begin{tabular}{|c|c|c|}
\hline Classes & $\begin{array}{l}\text { Competências prescritas para o gestor } \\
\text { público }\end{array}$ & $\begin{array}{c}\text { Rol de competências dos reitores } \\
\text { pesquisados (segundo todos os } \\
\text { entrevistados) }\end{array}$ \\
\hline $\begin{array}{c}\text { Fundamentais / } \\
\text { genéricas }\end{array}$ & $\begin{array}{l}\text { Comprometimento com o serviço público } \\
\text { Trabalho em equipe } \\
\text { Flexibilidade } \\
\text { Sensibilidade social } \\
\text { Negociação } \\
\text { Comunicação }\end{array}$ & $\begin{array}{l}\text { Liderança política (representação) } \\
\text { Flexibilidade } \\
\text { Diálogo (comunicação) } \\
\text { Trabalhar em equipe }\end{array}$ \\
\hline Organizacionais & $\begin{array}{l}\text { Conhecimento da administração pública } \\
\text { Capacidade de aprender }\end{array}$ & $\begin{array}{l}\text { Conhecimento da instituição } \\
\text { Habilidade política (negociação) }\end{array}$ \\
\hline
\end{tabular}




\begin{tabular}{|c|c|c|}
\hline & $\begin{array}{l}\text { Comunicação } \\
\text { Negociação } \\
\text { Planejamento educacional } \\
\text { Metodologias de ensino } \\
\text { Prospecção de conhecimentos em gestão } \\
\text { pública } \\
\text { Gestão de escola de governo } \\
\text { Conhecimentos de ferramentas de Tl e } \\
\text { sistemas governamentais }\end{array}$ & $\begin{array}{l}\text { Liderança acadêmica } \\
\text { Competência acadêmica } \\
\text { Captação de oportunidades }\end{array}$ \\
\hline Gerenciais & $\begin{array}{l}\text { Liderança inspiradora } \\
\text { Senso de direção } \\
\text { Comprometimento } \\
\text { Gestão integrada e estratégica de recursos } \\
\text { (capacidade de planejamento) } \\
\text { Visão/mente aberta } \\
\text { Capacidade de análise e síntese } \\
\text { Implementação equilibrada das políticas } \\
\text { públicas } \\
\text { Gestão de pessoas }\end{array}$ & $\begin{array}{l}\text { Liderança gerencial } \\
\text { Visão de futuro } \\
\text { Discernimento entre prioridades e } \\
\text { rotinas } \\
\text { Firmeza de propósitos } \\
\text { Lidar com conflitos } \\
\text { Saber decidir }\end{array}$ \\
\hline $\begin{array}{c}\text { Pessoais e } \\
\text { interpessoais }\end{array}$ & $\begin{array}{l}\text { Expansão contínua das fronteiras pessoais } \\
\text { Capacidade de articulação } \\
\text { Resolução de problemas } \\
\text { Iniciativa } \\
\text { Cooperação }\end{array}$ & $\begin{array}{l}\text { Cooperação } \\
\text { Habilidade política (articulação) } \\
\text { Tolerância } \\
\text { Ética } \\
\text { Ousadia } \\
\text { Paciência } \\
\text { Ponderação } \\
\text { Confiabilidade }\end{array}$ \\
\hline
\end{tabular}

Fonte: baseado em Amaral (2006); dados da pesquisa.

Ao mesmo tempo, pode-se afirmar que as funções administrativas apontadas anteriormente por Finger (1986) ainda constituem parte de sua função. No entanto, a elas são atribuídas, atualmente, um status mais burocrático, em oposição à expectativa de que reitor tenha foco em decisões estratégicas de longo alcance, de grande impacto e de acordo com as expectativas externas e internas.

Quando comparadas com os conhecimentos e habilidades bilíngues apontadas por Newcomer (1999), as competências desejadas para os reitores parecem não atender às expectativas, pelo menos em parte. Dentre os conhecimentos apontados, os reitores deveriam possuir basicamente conhecimentos relativos à "política de grupos de interesse", "ética", "procedimentos de políticas de alocação de recursos", conforme sugerem as 
competências apontadas pelos entrevistados. Por outro lado, somente as habilidades em "solução de conflitos e negociação" e "criação de consenso" parecem ser necessárias aos reitores, tal como indicado pelos entrevistados. Em sua maioria, aos reitores ainda faltaria o domínio da linguagem gerencial, a despeito de os entrevistados a apontarem como necessária, embora de forma nem sempre evidente.

Embora a literatura aponte a necessidade de formação de uma massa crítica de dirigentes que se percebam como tal, o que implica o desenvolvimento de competências distintivas e genéricas por meio de programas contínuos (LONGO, 1999; AMARAL, 2006), pelo menos no caso das instituições pesquisadas, não há nenhum tipo de ação estratégica nesse sentido. O próprio governo federal não possui um programa de desenvolvimento de gestores universitários, nem as próprias universidades. Como foi destacado por um dos vice-reitores, citado anteriormente (V4), "elegem-se pessoas e não se elege o administrador".

Em outras palavras, a universidade é uma espécie de arena política, em que os reitores (e vice-reitores) são eleitos por meio de um jogo político, em que a competência política é o principal critério objetivo, sendo a competência acadêmica uma espécie de pré-requisito legitimador, juntamente com a "experiência administrativa", que conferiria a suposta competência gerencial ao gestor. Observe-se que não se consideram "experiência" e "competências" como sinônimos, embora, de uma maneira geral, os pró-reitores tenham insinuado tal convergência de significado. Entretanto, tem-se de admitir que a gestão é também uma questão prática, o que implica ser possível o desenvolvimento de competências a partir das experiências cotidianas, e ao longo do tempo.

\section{Considerações Finais}

A despeito das peculiaridades da gestão pública, é crescente a adoção do repertório gerencial das empresas privadas por parte das organizações públicas. É razoável admitir que o setor público vem apresentando deficiências e demandando, assim, mudanças em sua estrutura e funcionamento. No entanto, não há uma unanimidade se essas mudanças devem assumir as formas organizacionais das empresas privadas, bem como sua lógica de ação.

A universidade não foge à regra, encontrando-se diante de três crises fundamentais, apontadas anteriormente. Admitindo-se que os gestores das universidades, de uma maneira geral, reconhecem a necessidade de suas instituições promoverem mudanças, eles identificam a necessidade de desenvolver determinadas competências, embora não necessariamente se alinhem quanto aos rumos que a instituição universitária deve seguir. Por outro lado, considerando-se a atual política do governo federal, as universidades federais manifestaram seu apoio, dado o investimento que seria realizado para sua expansão.

Dentre as competências apontadas, a única unanimidade se deu quanto à capacidade política, o que difere das competências prescritas para o gestor público em geral. É interessante observar que, embora a universidade tenha seus gestores (reitor e vice-reitor) "eleitos", oficialmente tal condição política não existe formalmente, pois a legislação ainda atribui ao presidente da república a escolha do dirigente máximo da instituição, que pode independer do resultado obtido junto à comunidade acadêmica dentro da universidade.

O repertório empresarial, embora presente nas instituições estudadas, ainda é incipiente, dadas as resistências quanto ao "modelo liberal" que o informa. Assim, o gestor bilíngue (NEWCOMER, 1999) ainda pode ser considerado um ideal a ser alcançado dentre os gestores entrevistados. De todo modo, sejam quais forem as competências desejadas e ideais para os gestores das universidades, a pesquisa deixou claro que não há nenhum tipo de preparação - um programa de desenvolvimento de gestores - para que os indivíduos assumam seus cargos e desempenhem suas funções eficazmente. Ao que parece, a capacidade política é tida como bastante e suficiente para o ocupante do cargo (vide Fig. 4), sendo tal capacidade reconhecida (e construída) a partir das histórias e trajetórias pessoais dos indivíduos, incluindo cargos anteriormente ocupados. A capacitação formal parece não ter a menor importância para que o indivíduo se torne um gestor, 
embora ressaltem que a ausência de conhecimentos administrativos seja um dificultador. No entanto, é importante destacar que, quando competindo pela ocupação do cargo de reitor, grupos de interesse se articulam em torno de um nome que os representa e que detenha aquela competência política. De todo modo, a competência política é tomada como fruto das experiências e realizações anteriores dos futuros gestores. É isso que os capacitaria a dirigir a instituição. De resto, pode-se perguntar: será mesmo suficiente, ou, será uma defesa corporativa de uma prática institucionalizada? Afinal, de uma forma ou de outra, todos demonstraram ser relativamente capazes de lidar com e gerenciar recursos muitas vezes escassos.

Finalmente, é importante assinalar que, embora a questão da aprendizagem não tenha sido aqui discutida, é evidente que a prática da gestão no contexto universitário contribui sobremaneira para o desenvolvimento das competências percebidas como desejáveis. Assim, sugerem-se pesquisas para investigar as formas pelas quais os gestores desenvolveram suas competências no exercício das funções gerenciais, de modo a ampliar o conhecimento acerca da temática.

\section{Referências}

ALVESSON, M; SKÖLDBERG, K. Reflexive methodology: new vistas for qualitative research. London: Sage, 2000.

AMARAL, H. K. Desenvolvimento de competências de servidores na administração pública brasileira. Brasília, Revista do Serviço Público, 57(4), pp.549-563, Out/Dez 2006.

BARDIN, L. Análise de conteúdo. Lisboa: Edições 70, 1977.

BENNIS, W. A invenção de uma vida. Rio de Janeiro: Campus, 1999.

BRANDÃO, H. P.; BAHRY, C. P. Gestão por competências: métodos e técnicas para mapeamento de competências. Brasília, Revista do Serviço Público, 56 (2), pp.179-194, Abr/Jun 2005.

BRESSER P. A administração pública gerencial: estratégia e estrutura para um novo Estado. Texto para Discussão n.09. Brasília: ENAP, 2001 (1996).

BRUYNE, P.; HERMAN, J.; SCHOUTHEETE, M. Dinâmica da pesquisa em ciências sociais. 5.ed. Rio de Janeiro: Francisco Alves, 1991.

CAVALCANTI, B. S.; OTERO, R. B. Novos padrões gerenciais no setor público: medidas do governo americano orientadas para o desempenho e resultados. Cadernos EBAP, n.86. Rio de Janeiro: FGV/EBAP, dezembro, 1997.

CHANLAT, J. F. Ciências sociais e management: reconciliando o econômico e o social. São Paulo: Atlas, 2000.

CUNHA, L. A. Reforma universitária em crise: gestão, estrutura e território. In TRINDADE, H. (Org.). Universidade em ruínas: na república dos professores. Petrópolis: Vozes, Rio de Janeiro: CIPEDES, 1999, p.125-148.

DENZIN, N. K.; LINCOLN, Y. S. Handbook of qualitative research. London: Sage, 1994.

FINGER, A. P. Liderança e gestão universitária. Florianópolis: Editora da UFSC, 1986.

FLICK, U. Desenho da pesquisa qualitativa. Coleção Pesquisa Qualitativa. Porto Alegre: Artmed, 2009.

. Entrevista episódica. In BAUER, M. W., GASKELL, G. Pesquisa qualitativa com texto, imagem e som: um manual prático. Petrópolis: Vozes, 2003, p.114-136.

KERR, C. Os usos da universidade. Fortaleza: Edições UFC, 1982. 
KLIKSBERG, B. A gerência na década de 90. Revista de Administração Pública, v.22, n.1,jan-mar, 1988, p.59-85. . Uma gerência pública para os novos tempos. Revista do Serviço Público, v.118, jan-jul, 1994, p.119-142.

KURZ, R. O colapso da modernização: da derrocada do socialismo de caserna à crise da economia mundial. Rio de Janeiro: Paz e Terra, 1993.

LIPIETZ, A. A audácia: uma alternativa para o século XXI. São Paulo: Nobel, 1991.

LONGO, F. A consolidação institucional do cargo de dirigente público. Revista do Serviço Público, Ano 54, n.2, abrjun, 2003, p.7-33.

MINAYO, M. C. de S. (Org.). Pesquisa social: teoria, método e criatividade. Petrópolis: Vozes, 2002.

MINTZBERG, H. Administrando governos, governando administrações. Revista do Serviço Público, Ano 49, n.4, outdez, 1998, p.148-164.

NEWCOMER, K. E. A preparação dos gerentes públicos para o século XXI. Revista do Serviço Público, Ano 50, n.2, abr-jun, 1999, p.5-18.

NUSSENZVEIG, H. M. (Org.). Repensando a universidade. Rio de Janeiro: Editora UFRJ/COPEA, 2004.

REED, M. Sociologia da gestão. Oeiras: Celta, 1997.

SANTOS, B.S. Pela mão de Alice: o social e o político na pós-modernidade. 9.ed. São Paulo: Cortez, 2003 [1.ed. 1995]. Cortez, 2004

A universidade do século XXI: para uma reforma democrática e emancipatória da Universidade. São Paulo:

SCHWELLA, E. Inovação no governo e no setor público: desafios e implicações para a liderança. Revista do Serviço Público, Ano 56, n.3, jul-set, 2005, p.259-276.

SILVERMAN, D. Interpreting qualitative data: methods for analysing talk, text and interaction. London: Sage, 1993.

TENÓRIO, F. G. O Estado empresário brasileiro: notas histórico-ideológicas. Cadernos EBAP, n.85. Rio de Janeiro: FGV/EBAP, julho, 1997.

TRIGUEIRO, M. G. S. Universidades públicas: desafios e possibilidades no Brasil contemporâneo. Brasília: Editora Universidade de Brasília, 1999.

TRIVIÑOS, A. N. S. Introdução à pesquisa em ciências sociais: a pesquisa qualitativa em educação. São Paulo: Atlas, 1987. 